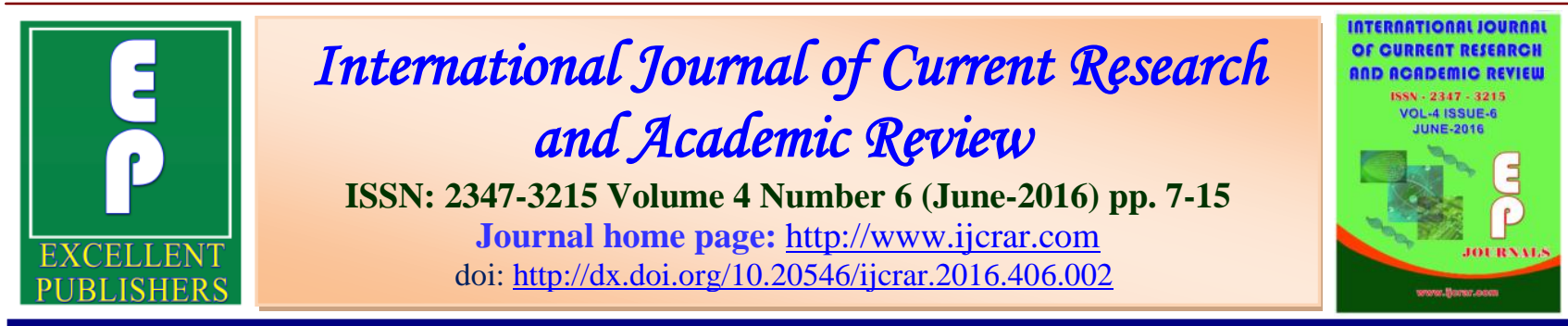

\title{
Determining Factors of Distance During 6-Minutes Walk Test in COPD
} Patients

\section{Moussouami Simplice Innocent ${ }^{1}$, Massamba Alphonse', Moulongo Jean Georges André ${ }^{1}$, Bazaba Kayilou Jean Michel ${ }^{1}$, Mboussa Joseph ${ }^{2}$ and Kayembe Ntumba Jean Marie ${ }^{3}$}

${ }^{1}$ Laboratoire de Physiologie de l'Effort et de Biomécanique, Institut Supérieur d'Education Physique et Sportive, Université Marien NGOUABI, Brazzaville, Congo

${ }^{2}$ Département de Médecine, Faculté des Sciences de la Santé, Université Marien NGOUABI et Service de Pneumologie, CHU de Brazzaville

${ }^{3}$ Département de Médecine, Faculté de Médecine, Université de Kinshasa et Service de Pneumologie, Cliniques universitaires de Kinshasa, Kinshasa, République Démocratique du Congo

\section{*Corresponding author}

\begin{tabular}{|c|c|}
\hline KEYWORDS & A B S T R A C $\mathbf{T}$ \\
\hline $\begin{array}{l}\text { COPD; } \\
\text { 6-minute walk test; } \\
\text { Inspiratory capacity; } \\
\text { Hyperinflation; } \\
\text { Quality of life. }\end{array}$ & $\begin{array}{l}\text { In stable COPD, identify and analyze the factors determining six minutes } \\
\text { walking distance and dyspnea the end of the test. Patients were evaluated by } \\
\text { test of lung function. St Georeges respiratoiry questionnaire (SGRQ) and } 6 \\
\text { MWT with inspiratory capacity measurements (IC) continuous oxymetry. } \\
\text { Eigthty-two patients (mean } \mathrm{FEV}_{1}: 56 \pm 19 \% \text { predicted) were studied. Mean 6- } \\
\text { minutes walking distance was } 477 \pm 89 \mathrm{~m} \text { ( } 72 \pm 14 \mathrm{PV} \text { ). Walking distance } \\
\text { during 6MWT(m) was correlated with } \mathrm{FEV}, \mathrm{C}_{1}, \mathrm{CI} / \mathrm{TLC} \text { ratio, TLC, pré-test CI } \\
\text { and DLCO/VA. When expressed as percent of predicted values, walking } \\
\text { distance was correlated with FRC, pre-test IC and SGRQ activity score. End } \\
\text { test dyspnea was correlated with FRC, pré-test dyspnea and SGRQ activity } \\
\text { and total scores. The factors determining 6-minutes walking distance and } \\
\text { end-test dyspnea are complex and include both functional and non functional } \\
\text { factors. In COPD, 6MWT is thus an investigation that has additional } \\
\text { integrative value. }\end{array}$ \\
\hline
\end{tabular}

\section{Introduction}

Chronic obstructive pulmonary disease (COPD) is characterized by not fully reversible airway obstruction. This obstruction, the most common cause is smoking, is gradually and severity is assessed primarily by the GOLD guidelines
(Global initiative for chronic obstructive lung disease.). The degree of bronchial obstruction, appreciated by the expiratory volume per second (FEV) is a prognostic factor (Anthonisen et al., 1994; Anthonisen et al., 1986). 
But it has recently emerged that other factors, in particular functional, were decisive for evaluating the prognosis and survival of these patients. The index body mass index, airflow obstruction, dyspnea functional, exercise capacity (BODE) (Celli et al., 2004) composite index taking FEV, distance from the six-minute walk test (CT), degree of dyspnea index body mass is maintained routinely used to assess the prognosis of these patients; but also the impact of therapeutic interventions as the revalidation (Beaumont et al., 2011). TDM also reflects, more than ergospirometry on bicycle, activities of daily living (Guyatt et al., 1991; Garcia-Rio et al., 2009). It emerged recently that the poor performance in CT was associated with increased mortality in COPD with a lower FEV 50\% predicted (VP) (Casanova et al., 2008).

The measures needed to perform quality YDM, as recommended by the American Thoracic Society (ATS) (Statement, 2002), are the qualification of the number of meters made and dyspnea before and end of the test. In this study, we evaluated in COPD in stable condition if respiratory functional factors, the development of a dynamic destruction or distension during the test (Callens et al., 2009) or even the quality of life determine the distance and end of the test dyspnea.

\section{Methods}

\section{Patients}

From September 2013 to September 2014, all patients in stable condition BPCIO of GOLD stage I to IV, presenting an outpatient basis at the pulmonology department of the Brazzaville University Hospital for lung function tests were evaluated prospectively.
They were selected based on their medical history, their habits and tabagismes spirometry results showing FEV / vital capacity (VC) less than 70\%. None had presented exacerbation in the previous month.

Informed consent was obtained. The study had previously been accepted by the ethics committee of the Medical Society of the Congo.

\section{Measures}

\section{First Evaluation}

Pulmonary function tests were performed in all patients. They completed the Respiratory Questionnaire St. George's (SGRQ) (Piperno et al., 2000), followed by TDM habituation, conducted according to the ATS guidelines. The standards used to evaluate performance TDM are those of Troosters et al. (1999)

\section{Second Evaluation}

During the same week, a second CT scan was performed, with additional measures of inspiratory capacity (IC) and continuous oximetry.

A first IC measurement was performed at rest, before MDA. The CI was measured using a portable spirometer (Spiro BT 100, Medical Electronic Construction, Brussels, Belgium) after patient education and training. After obtaining from April to June volumes end expiration successive stable, we asked them to inspire total lung capacity (CTP), then breathe normally. The measurements were repeated for a maximum variation of $5 \%$ on two consecutive measurements, and we retained the highest value (Marin et al., 2001). At the end of TDM, a measure of CI was also carried out in the corridor, immediately after walking, 
using the same portable spirometer. Dyspnea was assessed before and after MDD with the Borg Scale (Borg et al., 1982).

The distance of the CT and end of the test dyspnea were correlated with the severity of airway obstruction (expiratory volume in one second) to distention (functional capacity (FRC), total lung capacity (CPT) and CI report / CPT), the dynamic distension during the test (modification of the CI during the test), the oxygen desaturation and quality of life (SGRQ).

\section{Statistical Analysis}

The results are expressed as mean \pm standard deviation. Comparing the quantitative data was carried out by a paired $\mathrm{t}$ test. Univariate analyzes were performed by calculating the Pearson correlation coefficient, in order to study the existence of a relationship between various clinical and functional variables and walking distance (in meters and percentage VP) or the end of dyspnea test.

Multivariate analysis was performed using the method of logistic regression to determine step by step what the variables independently correlated with walking distance (in meters and percentage VP) and test end dyspnoea.

The differences were considered statistically significant when the critical value of uncertainty $\mathrm{p}$ is less than 0.05 .

\section{Results and Discussion}

A total of 82 patients (59 men and 23 women) were studied COPD. All were (former) smoking and classified GOLD stages I to IV. None were oxygeno dependent. The average age was $62 \pm 10$ years. The mean FEV was $1.6 \pm 0.6(56 \pm 18$ of the VP). The SGRQ score was $41 \pm 20 \%$ for the item " symptoms " and $59 \pm 23$ for " activities ". Main functional and anthropological data are summarized in Table 1.

The distance at the end of CT was $477 \pm$ $89 \mathrm{~m}$, or $72 \pm 14 \%$ of the VP and CT was associated with a significant increase in dyspnea $(0.4 \pm 0.7$ at the beginning of test 3 , $9 \pm 2.1$ end of the test; $p<0,0001)$ and a significant increase in $\mathrm{O} 2$ saturation $(94 \pm$ $11-91 \pm 5 \% ; \mathrm{p} 0.0001)$. For the population as a whole, the TDM was accompanied by the development of a dynamic distension since the CI decreased from $2.2 \pm 0.6 \mathrm{~L}$ standing at $1.8 \pm 0.7 \mathrm{~L}(\mathrm{p}<0,0001)$ late test, or $111 \pm 34-89 \pm 30 \%$ of the VP $(p<0,0001)$. Nineteen of 81 patients $(23 \%)$ did not develop dynamically distension to the effort.

Predictors level dynamic distension in $\Delta \mathrm{CI}$ efforts as percentage of VP) were $\mathrm{FEV}$, a percentage of the VP $(p=0.0026)$ and the FIU in liters $(p=0.0029)$. All parameters measured during MDA are summarized in Table 2.

Table 3 summarizes the significant relationships in univariate analysis, and Table 4 in multivariate analysis with the distance in meters and percentage of the VP, and dyspnea end CT.

The end dyspnea MDD was, she, well correlated with FEV, VP percentage $(r=-$ 0.37), with the FIU, VP percentage $(r=$ $0.33)$ with the $\triangle \mathrm{CI}$ early $\mathrm{CT}$; $\mathrm{L}(\mathrm{r}=0.26)$ and with the carbon monoxide diffusing capacity (DLco), percentage VP $(r=-0.25)$.

In multivariate analysis, the distance covered in meters CT correlated with FEV (L), CPT (L), the IC (L) before the test and the report DLCO / VA (Table 4); these four variables explained $35 \%$ of variance of CT 
in meters. This same distance as a percentage of the VP was significantly correlated to the FIU (L and percent predicted), the CI (L) before the test, and the score of Saint George's activity. These four variables explained $38 \%$ of variance of CT as a percentage of the VP.

Dyspnea at the end of TDM was about that correlated with the FIU (L), with the start of test and dyspnea with activities and total SGRQ scores (Table 4); and 35\% of the variance was accounted for by these variables 4 .

This study suggests that the co-variables that are related to the distance covered during the 6-minute $\mathrm{CT}$ in patients with COPD include FEV, the FRC and TLC, IC resting DLCO / VA and score Saint-Georges on. For dyspnea at the end of TDM, the study found as covariates of the FIU, dyspnea before the test and score Saint-Georges and total activity.

Our study, however, suffers from limitations due to the small sample size, but also because some parameters that could affect the results of the walk test as exacerbations, the degree of emphysema, body composition, muscle strength devices, cardiac dysfunction induced by distension have not been investigated. These limitations invoked do not affect completely the power of our observations. This study is in any case the first of its kind in our environment, including proven patients.

Some differences in the variables related to the distance to the TDM absolute or percentage of the VP called a comment. For example, FEV is a determinant of the distance traveled in meters; but it is no longer when it is expressed as a percentage of the VP. In reality, the walk in the normal individual is related to age, gender and size, factors that also determine lung volumes so it is not surprising that their decisive less evident in the distance expressed in percentage of the VP.

Apart from the effect $p=0,0026 t$ expected FEV on the walking distance, we observed that the parameters indicating a distension as the CPT, the FIU, the IC off and the IC / TLC ratio are correlated negatively with the walk, in agreement with observations of other authors. Similarly, DLCO / VA correlates with distance. Together, these observations suggest that the emphysema phenotype is associated with worse performance in the walk test. In our study, no emphysema evaluation CT data is available to confirm this; but analysis of da ECLIPSE cohort as other studies (Spruit et al., 2010; Lee et al., 2008) show the scope or extent of emphysema measured by CT scan are correlated negatively with the distance. We found no correlation between desaturation during the TDM and distance (or dyspnea); but note that no patient suffering from resting hypoxemia and desaturation than the average observed in the effort was modest.

We have not found any correlation between the parameters that reflect a dynamic test at the end of distension as the CI end TDM or $\triangle \mathrm{CI}$ over TDM and distance or the end of the test dyspnea although the majority of our population with COPD $(77 \%)$ actually develops a dynamic distension during the walk test. This observation is consistent with the results obtained by Callens et al., in 52 patents COPD, but contradict the data of Marin et al., obtained in 72 COPD patients where $\Delta \mathrm{CI}$ correlated with the performance and dyspnea associated with the walking test. Regarding the dynamics distension, this difference seems apparent to the extent that the $\mathrm{CI}$ rest is raised by all these studies, such as ours (CI rest is same the only significant parameter in absolute and VP) as a predictor of distance. 
Int.J.Curr.Res.Aca.Rev.2016; 4(6): 7-15

Table.1 Anthropometric characteristics and plethysmographic of 82 patients

bronchoneumopathie chronic obstructive pulmonary disease (COPD) and results in respiratory questionnaire St. George's

\begin{tabular}{lcc}
\hline & Average & Standard Deviation \\
\hline Age (years) & 61.91 & 9.92 \\
BMI kg/m ${ }^{2}$ & 24.95 & 5.004 \\
Smoking (pack-years) & 50.5 & 27.61 \\
FEV (L) & 1.569 & 0.5794 \\
FEV (\%\% predicted) & 56.37 & 18.67 \\
CRF (L) & 4.71 & 1.381 \\
CRF (\%\% predicted) & 146 & 40.17 \\
CPT (L) & 6.835 & 1.32 \\
CPT (\% predicted) & 114.9 & 20.06 \\
Saint-George's TOTAL (\%) & 41.61 & 19.56 \\
Saint-George's syndromes & 45.61 & 22.94 \\
Saint-George's activity & 58.65 & 23.43 \\
DCLO (\% predicted) & 52.60 & 17.03 \\
DCLO/VA & 61.22 & 20.82 \\
Sex & $59 / 23=2,6$ & \\
\hline Abbreviations: BMI, body
\end{tabular}

Abbreviations: BMI, body mass index; FEV, maximum expiratory volume; FRC, functional residual capacity, CPT, total lung capacity; DCLO, carbon monoxide diffusing capacity.

Table. 2 Results of the measurements taken during the walk test (CT) scans of 82 patients with chronic obstructive bronchoneumopathie (COPD)

\begin{tabular}{|c|c|c|}
\hline & Average & Standard Deviation \\
\hline Distance $(\mathrm{m})$ & 477.3 & 89.43 \\
\hline Distance (\% prédit) & 72.25 & 13.82 \\
\hline CI max rest $(\mathrm{L})$ & 2.234 & 0.624 \\
\hline CI max rest (\% predited) & 112.2 & 34.43 \\
\hline CI end TDM (L) & 1.814 & 0.6557 \\
\hline CI end TDM (\% predited) & 89.19 & 29.66 \\
\hline$\Delta \mathrm{CI}(\mathrm{L})$ & 0.4922 & 0.3509 \\
\hline$\Delta \mathrm{CI}(\%$ predited $)$ & 25.73 & 20.77 \\
\hline Borg pré-TDM & 0.4074 & 0.7379 \\
\hline Borg post-TDM & 3.938 & 2.117 \\
\hline$\Delta$ Borg & 3.556 & 2.055 \\
\hline Saturation end pre-TDM (\%) & 90.98 & 5.02 \\
\hline Saturation pré-TDM (\%) & 95.02 & 1.844 \\
\hline
\end{tabular}

Abbreviations: CI, inspiratory capacity; Borg, Borg scale. 
Int.J.Curr.Res.Aca.Rev.2016; 4(6): 7-15

Table.3 Correlations significant in univariate analysis between the distance to the walking test (CT) in meters or percentage of predicted or dyspnea at the end of TDM, assessed by the Borg scale and various parameters

\begin{tabular}{|c|c|c|c|c|c|c|}
\hline \multirow[b]{3}{*}{ FEV (L) } & \multicolumn{2}{|c|}{$\begin{array}{l}\text { Distance traveled } \\
\text { TDM (m) }\end{array}$} & \multicolumn{2}{|c|}{$\begin{array}{c}\text { Distance traveled } \\
\text { TDM }(\%)\end{array}$} & \multicolumn{2}{|c|}{$\begin{array}{c}\text { Dyspnea and TDM } \\
\text { (Borg) }\end{array}$} \\
\hline & $\mathrm{r}$ & $\mathrm{p}$ & $\mathrm{r}$ & $\mathrm{P}$ & $\mathrm{r}$ & $\mathrm{p}$ \\
\hline & 0.54 & $<0.001$ & 0.33 & 0.003 & 0.27 & 0.01 \\
\hline FEV (\% predited) & 0.49 & $<0.001$ & 0.53 & $<0.001$ & 0.40 & $<0.001$ \\
\hline CRF (L) & 0.28 & 0.01 & 0.41 & $<0.001$ & 0.35 & $<0.001$ \\
\hline CRF (\% predited) & 0.27 & 0.02 & 0.31 & 0.005 & 0.35 & 0.001 \\
\hline CPT (L) & 0.13 & 0.24 & 0.34 & 0.002 & 0.30 & 0.002 \\
\hline СРТ (\%) & 0.22 & 0.05 & 0.20 & 0.08 & 0.01 & 0.007 \\
\hline CI rest (L) & 0.40 & $<0.001$ & 0.22 & 0.05 & 0.23 & 0.93 \\
\hline $\mathrm{CI}$ rest $(\%)$ & 0.04 & 0.70 & 0.08 & 0.48 & 0.19 & 0.04 \\
\hline CI end TDM (L) & 0.42 & $<0.001$ & 0.26 & $<0.001$ & 0.01 & 0.92 \\
\hline CI end TDM (\%) & 0.13 & 0.27 & 0.09 & 0.02 & 0,26 & 0.02 \\
\hline$\Delta \mathrm{CI}(\mathrm{L})$ & 0.06 & 0.59 & 0.07 & 0.45 & 0.33 & 0.003 \\
\hline$\Delta \mathrm{CI}(\%)$ & 0,21 & 0.06 & 0.21 & 0.52 & 0.19 & 0.09 \\
\hline $\mathrm{CI} / \mathrm{CPT}$ & 0.48 & $<0.001$ & 0.44 & 0.06 & 0.48 & 0.05 \\
\hline $\mathrm{Sa}_{2}$ pré-TDM & 0.30 & 0.007 & 0.20 & $<0.001$ & 0.22 & 0.05 \\
\hline DCLO (\%) & 0.21 & 0.10 & 0.25 & 0.07 & 0.25 & 0.31 \\
\hline DCLO/VA & 0.01 & 0.93 & 0.01 & 0.04 & 0.13 & 0.01 \\
\hline Borg pre-TDM & 0.22 & 0.05 & 0.28 & 0.92 & 0.28 & 0.14 \\
\hline Borg post-TDM & 0.14 & 0.21 & 0.20 & 0.07 & l & l \\
\hline$\Delta$ Borg & 0.09 & 0.45 & 0.12 & 0.27 & I & I \\
\hline QRSG activities & 0.45 & $<0.001$ & 0.52 & $<0.001$ & 0.47 & $<0.001$ \\
\hline QRSG symptomes & 0.24 & 0.03 & 0.33 & 0.003 & 0.30 & 0.006 \\
\hline QRSG total & 0.42 & $<0.001$ & 0.53 & $<0.001$ & 0.36 & 0.001 \\
\hline IMC & 0.20 & 0.07 & 0.04 & 0.72 & 0.20 & 0.84 \\
\hline
\end{tabular}

Abbreviations: CI, inspiratory capacity; CPT, total lung capacity; FEV, maximum expiratory volume; FRC, functional residual capacity; Sa02 pre-TDM, oxygen saturation; DCLO, carbon monoxide diffusing capacity; DCLO / VA, diffusing capacity for carbon monoxide reduced to alveolar volume; SGRQ, Respiratory Questionnaire of St. George; BMI, body mass index. 
Int.J.Curr.Res.Aca.Rev.2016; 4(6): 7-15

Table.4 Correlations significant in univariate analysis between the distance to the walking test (CT) in meters or percentage of predicted or dyspnea at the end of TDM, evaluated by Borg scale and various parameters

\begin{tabular}{lccc}
\hline & $\begin{array}{c}\text { Distance traveled } \\
\text { TDM (m) }\end{array}$ & $\begin{array}{c}\text { Distance traveled } \\
\text { TDM (\%) }\end{array}$ & $\begin{array}{c}\text { Dyspnea and } \\
\text { TDM (Borg) }\end{array}$ \\
\hline FEV (L) & 0.0036 & NS & NS \\
CRF (L) & NS & 0.0009 & 0.034 \\
CRF (\% predited) & NS & 0.0151 & $/$ \\
CPT (L) & 0.0016 & NS & NS \\
CI rest (L) & 0.0035 & 0.0215 & NS \\
DCLO/VA & 0.0070 & NS & NS \\
Dyspnea pre-TDM (Borg) & NS & NS & 0.0562 \\
QRSG Activities & NS & $<0.0001$ & 0.0006 \\
QRSG Total & NS & NS & 0.0258 \\
\hline
\end{tabular}

Abbreviations: CI, inspiratory capacity; CPT, total lung capacity; FEV, maximum expiratory volume per second; FRC, functional residual capacity; DCLO, carbon monoxide diffusing capacity; SGRQ, Respiratory Questionnaire St. George.

Indeed, the rest of CI also integrates dynamic distension as illustrated by the fact that salbutamol in our population of COPD, improves CI rest when patients have a limitation of expiratory flow and does not affect it in the condition reverse (Boni et al., 2002).

Several factors could explain then that the test end IC has no predictive value in our study. The explanation does not seem linked to a greater propensity to develop a dynamic distension in the study by Marin et al., On the contrary, the decrease of our population CI late effort was greater $(-492 \mathrm{~mL}$ versus $271 \mathrm{~mL})$. It is possible that the methodological differences in the measurement of the end of the test ICs explain these conflicting results. End of the test, a single measurement was performed in our study while Marin et al. obtained the average of two measurements. L a single measure, however, seems better in this particular circumstance, because it was assumed (Marin et al., 2001) and demonstrated that $\mathrm{CI}$ is normalized in less than 3 minutes after exercise and therefore repeated measures were training a sub- estimation of dynamic hyperinflation. The team of Yan et al., has also demonstrated by esophageal pressure measurements at rest and at year end, in 15 COPD, that the efforts made during the IC maneuvers were reliable, reproducible and allowed to properly estimate changes in volume endtidal during exercise. Recent observations of Guenette et al., are in agreement with our results and serve to dispel commonly held opinion that the development of a dynamic effort to distension is related to the endurance time and dyspnoea. In this study, the authors compared 65 COPD who develop dynamic distension exercise and 65 did not develop in FEV equivalent, and found that dyspnea and endurance time were similar in both groups. Dyspnea was determined by the level of the slope inflection VT / VE, otherwise similar between the two groups and not by the level of distension (Guenette et al., 2001).

Our study also found, in agreement with recent data (Spruit et al., 2010), a correlation between the quality of life (essentially the score of the SGRQ activity) and the distance of the walk test or dyspnea. This observation 
is not surprising inasmuch as the assessment of quality of life brings together into a single variable the overall impact of COPD. Multivariate analyzes also show that dyspnea score assessed by the Medical Research Council and the distance traveled in CT are part of the five factors (the others are coughing, wheezing and anxiety score) that help explain $50 \%$ of the variance of the SGRQ (Jones, 2001).

In conclusion, the factors that determine the performance and dyspnea during the sixminute walk test are complex and depend on functional and non-functional factors. The six-minute walk test thus appears as a test of exploration integral value in COPD.

\section{Declaration of Interest}

The authors declare having no conflicts of interest related to this article.

\section{References}

Anthonisen, N.R., Connett, J.E., Kiley, J.P., et al. 1994. Effets of smoking intervention and the use of an inhaled anticholinergic bronchodilator on the rate of FEV1. Lung Health Study. JAMA, 272: 1497-505.

Anthonisen, N.R., Weight, E.C., Hodgkin, J.E. 1986. Prognostic in chronic obstructive pulmonary disease. Am. Rev. Respir. Dis., 133: 14-20.

Beaumont, M., Reyschler, G., Le Ber-Moy, C., et al. 2011. The effects of a pulmonary rehabilitation program in relation to the severity of COPD. Rev. Mal. Respir., 28: 297-305.

Boni, E., Corda, L., Franchini, D., et al. 2002. Volume effect and exertional dyspnoea after bronchodilator in patients with COPD with and without expiratory flow limitation at rest. Thorax, 57: 528-32.
Borg, G.A. 1982. Psychophysical bases of perceived exertion. Med. Sci. Sports Exerc., 14: 377-81.

Callens, E., Graba, S., Gillet-Juvin, k., et al. 2009. Measurement of dynamic hyperinflation after a 6-minute walk test in patients with COPD. Chest, 136: 1466-72.

Casanova, C., Cote, C., Marin, J.M., et al. 2008. Distance and oxygen desaturation during the 6-min walk test as predictors of long-term mortality in patients with COPD. Chest, 134: 746-52.

Celli, B.R., Cote, C.G., Marin, J.M., et al. 2004. The body-mass index, airflow obstruction, dyspnea, and exercise capacity index in chronic obstructive pulmonary disease. N. Engl. J. Med., 350: 1005-12.

Garcia-Rio, F., Lores, V., Mediano, O., et al. 2009. Daily physical activity in patients with chronic obstructive pulmonary disease is mainly associated with dynamic hyperinflation. Am. J. Respir. Crit. Care Med, 180: 506-12.

Global initiative for chronic obstructive lung disease. Disponible sur le site: htpp://ww.gold.org

Guenette, A.J., Webb, K.A., O’Donnell, D.E. 2001. Does dynamic hyperinflation contribute to dyspnoea during exercise in patients with COPD? Eur. Respir. J., 10: 315-22.

Guyatt, G.H., Townsend, M., Keller, J., et al. 1991. Measuring functional status in chronic lung disease: conclusions from a random control trial. Respir. Med., 85: 17-21.

Jones, P.W. 2001. Health status measurement in chronic obstructive pulmonary disease. Thorax, 56: 880-7.

Lee, Y.K., Oh, Y.M., Lee, J.H., et al. 2008. Quantitative assessment of emphysema, air trapping, and airway 
thickening on computed tomography. Lung, 186: 157-65.

Marin JM, Carrizo SJ, Gascon M, et al. 1999. Inspiratory capacity, dynamic hyperinflation, breathlesssness, and exercise performance during the 6minute-walk test in chronic obstructive pulmonary disease. Am. J. Respir. Crit. Care Med., 163: 1395-9.

Piperno, D. 2000. Le questionnaire respiratoire de Saint-Georges. In : La réhabilitation respiratoire-guide pratique. Paris : Imothep/Maloine, p.119-27.

Spruit, M.A., Walking, M.L., Edwards, L.D., et al. 2010. Evaluation of COPD longitudinally to identify predictive surrogate end-points (ECLIPSE) study investigators. Determinants of poor 6min walking distance in patients with COPD: the ECLIPSE cohort. Respir. Med., 104: 849-57.

Statement. A.T.S. 2002. Guidelines for the six minute walk test. Am. J. Respir. Crit. Care Med., 166: 111-7.

Troosters, T., Gosselinck, R., Decramer, M. Six minute walking distance in healthy elderly subjects. Eur Respir J 1999; 14: 270-4

Yan, S., Kaminski, D., Sliwinski, P. 2007. Reliabily of inspiratory-capacity for estimating end-expiratory lung volume changes during exercise in patients with chronic obstructive pulmonary disease. Am. J. Respir. Crit. Care Med., 156: 55-9.

\section{How to cite this article:}

Moussouami Simplice Innocent, Massamba Alphonse, Moulongo Jean Georges André, Bazaba Kayilou Jean Michel, Mboussa Joseph, Kayembe Ntumba Jean Marie. 2016. Determining Factors of Distance During 6-Minutes Walk Test in COPD Patients. Int.J.Curr.Res.Aca.Rev.4(7): 7-15. doi: http://dx.doi.org/10.20546/ijcrar.2016.406.002 